\title{
Surgical Correction of Severe Bilateral Thumb Pincer-Nail Deformity
}

\author{
Scott T. Van Duzer \\ TJU - The Philadelphia Hand Center, PC \\ John S. Taras \\ TJU - The Philadelphia Hand Center, PC
}

Follow this and additional works at: https://jdc.jefferson.edu/orthofp

Part of the Orthopedics Commons

Let us know how access to this document benefits you

\section{Recommended Citation}

Van Duzer, Scott T. and Taras, John S., "Surgical Correction of Severe Bilateral Thumb PincerNail Deformity" (2006). Department of Orthopaedic Surgery Faculty Papers. Paper 7.

https://jdc.jefferson.edu/orthofp/7

This Article is brought to you for free and open access by the Jefferson Digital Commons. The Jefferson Digital Commons is a service of Thomas Jefferson University's Center for Teaching and Learning (CTL). The Commons is a showcase for Jefferson books and journals, peer-reviewed scholarly publications, unique historical collections from the University archives, and teaching tools. The Jefferson Digital Commons allows researchers and interested readers anywhere in the world to learn about and keep up to date with Jefferson scholarship. This article has been accepted for inclusion in Department of Orthopaedic Surgery Faculty Papers by an authorized administrator of the Jefferson Digital Commons. For more information, please contact: JeffersonDigitalCommons@jefferson.edu. 
She was scheduled for surgical correction by modification of previously described techniques (1). Beginning with the left thumb a digital block was performed and the affected digit was exsanguinated. The nail plate was sharply removed without damaging the underlying sterile and germinal maxtrix. The curved nail bed was then elevated off the underlying distal phalanx (Figure 2). On the left side, a dermal graft was obtained from the hypothenar eminence which was closed primarily. This was harvested as a full thickness graft which was then de-epithelialized (Figures 3 and 4). The dermal graft was divided into two equal pieces and placed in the area of the lateral nail folds, filling in the defects which had been present. The nail bed was sutured back over the graft to the lateral nail folds with 5-0 chromic suture. The nail bed now had a less curved and more natural flattened appearance (Figure 5). The curved nail plate was discarded and silicone sheeting was placed into the nail fold as a stent. On the right side a similar procedure was performed, however, instead of harvesting dermal grafting from the patient, a suitably sized piece of Integra collagen graft (Integra LifeSciences Corporation, Plainsboro, NJ.) was used in place of the dermal graft. This was accomplished by removing the silicone membrane layer of the Integra bi-laminate and using only the collagen-glycosaminoglycan matrix component (Figure 6). This allows the collagen matrix component of the Integra to be wholly implanted. This was then positioned as the dermal graft had been into the lateral nail defects. The remainder of the procedure was performed as previously described.

The patient reported resolution of her pain and soft tissue pinching sensation which she had preoperatively. Her thumbs nails have re-grown in a more normal and flattened appearance (Figure 7). There was good adherence between the nail plate and the underlying nail bed.

Pincer-nail or trumpet nail deformity has been well described in the literature $(1,2,3,4)$. It is characterized by excessive curvature of the nail plate, more pronounced distally than proximally (1). Viewed end-on, the abnormally shaped nail resembles an omega (Figure 1). This abnormal curvature may result in pinching of the underlying nail bed and soft tissue resulting in chronic pain. The etiology of the nail deformity has been variously attributed to a variety of developmental, systemic, acquired, and external agents (1). The deformity must be distinguished from nail distortion resulting from bacterial or fungal infections. It may affect the nails of the hands and the feet and appears to predominantly affect the nails of the thumbs and great toes.

Various methods have been described to treat pincer-nail deformity. These include dermal grafting, in a procedure similar to the technique described above (1), surgical avulsion of the nail plate (2), surgical revision of the nail bed (4), nail leveling with a grinder and application of pliant plastic plates (5), and nail bed elevation with hard-palate mucosal grafting (6). These various procedures have differing risks and benefits including recurrence of the deformity, non-adherence of the nail plate to the underlying nail bed, and the morbidity and complexity associated with graft donor sites. We report a slight modification of the technique described by Brown et al. (1) in that the entire nail bed excepting the germinal matrix is elevated off the distal phalanx. In our case we also demonstrate the use of the collagen-glycosaminoglycan matrix portion of Integra bilaminate to avoid dermal harvest site and grafting. There did not appear to be any significant difference in the curvature of the regenerated nail in the digit where Integra was used compared with the digit in which dermal auto-grafting was used. It is assumed that Alloderm could also be used in a similar manner, although we have not used it for 
treatment of pincer-nail deformity. In this case we achieved painless and normal appearing nail contour with good adherence of the nail plate to the nail bed without disrupting the germinal matrix. In addition we have demonstrated a technique that utilizes a readily available collagen-glycosaminoglycan matrix to avoid dermal harvesting and grafting.

(No benefits in any form have been received or will be received from a commercial party related directly or indirectly to the subject of this article.) 


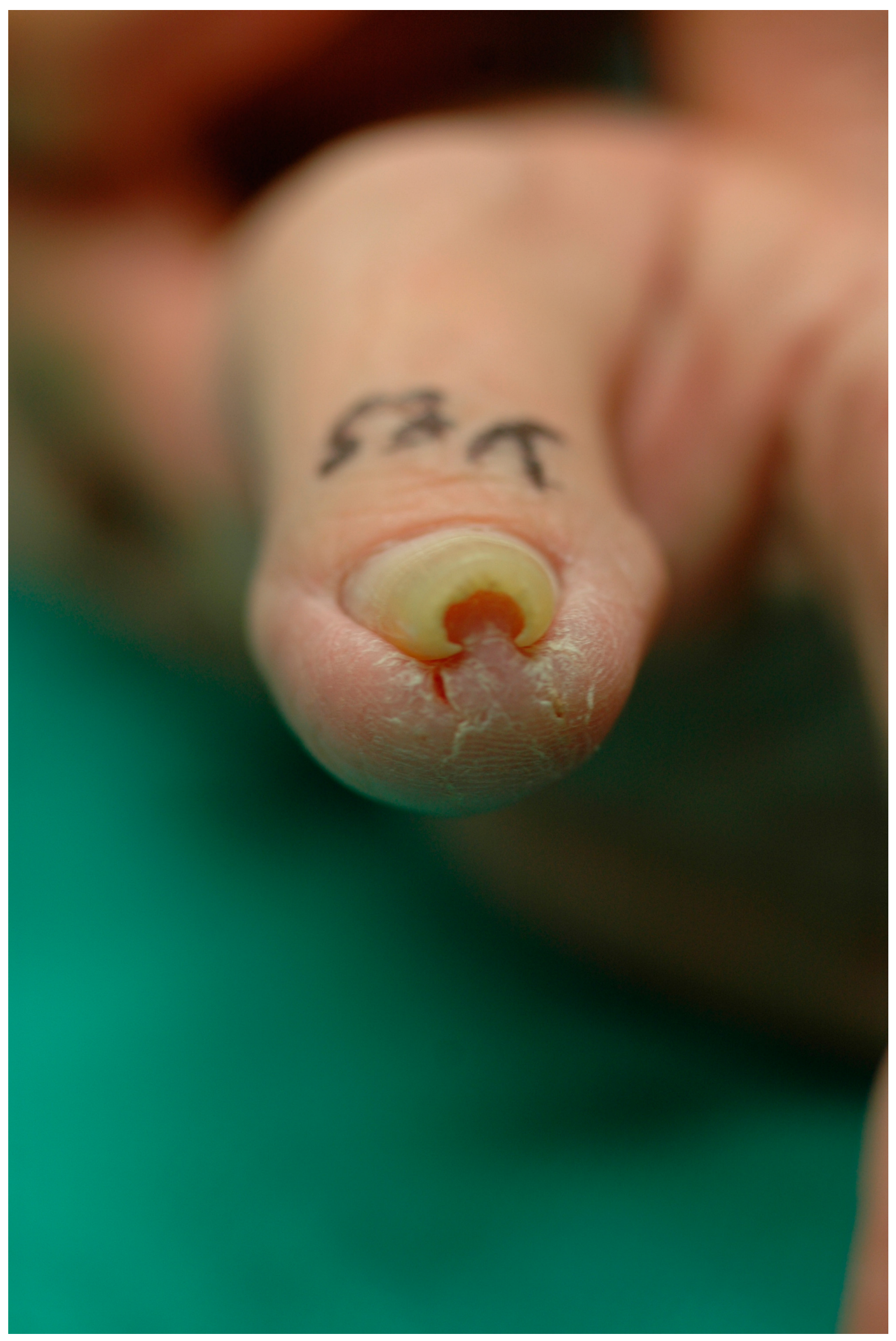




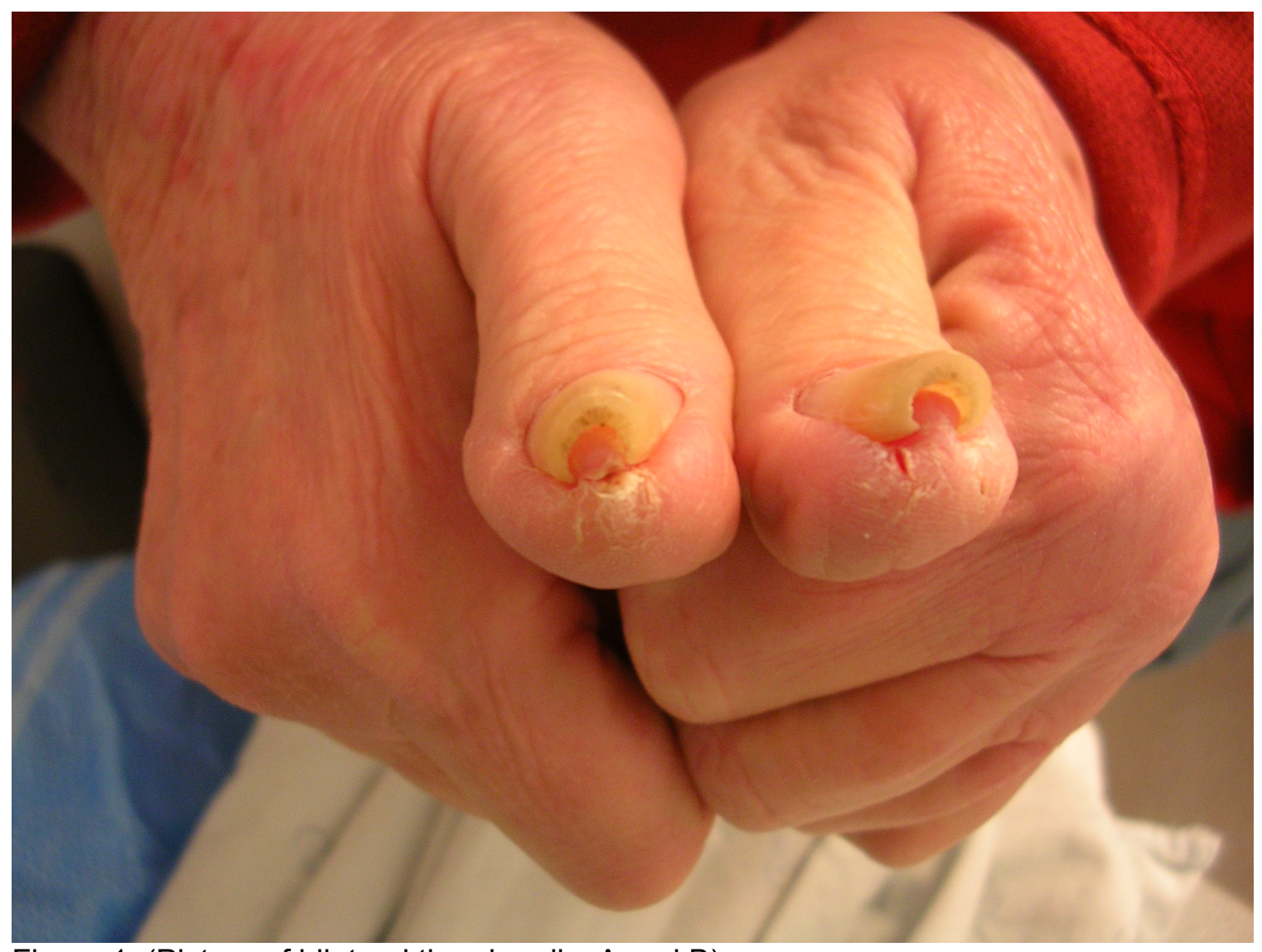

Figure 1. (Picture of bilateral thumb nails; $A$ and $B$ ) 


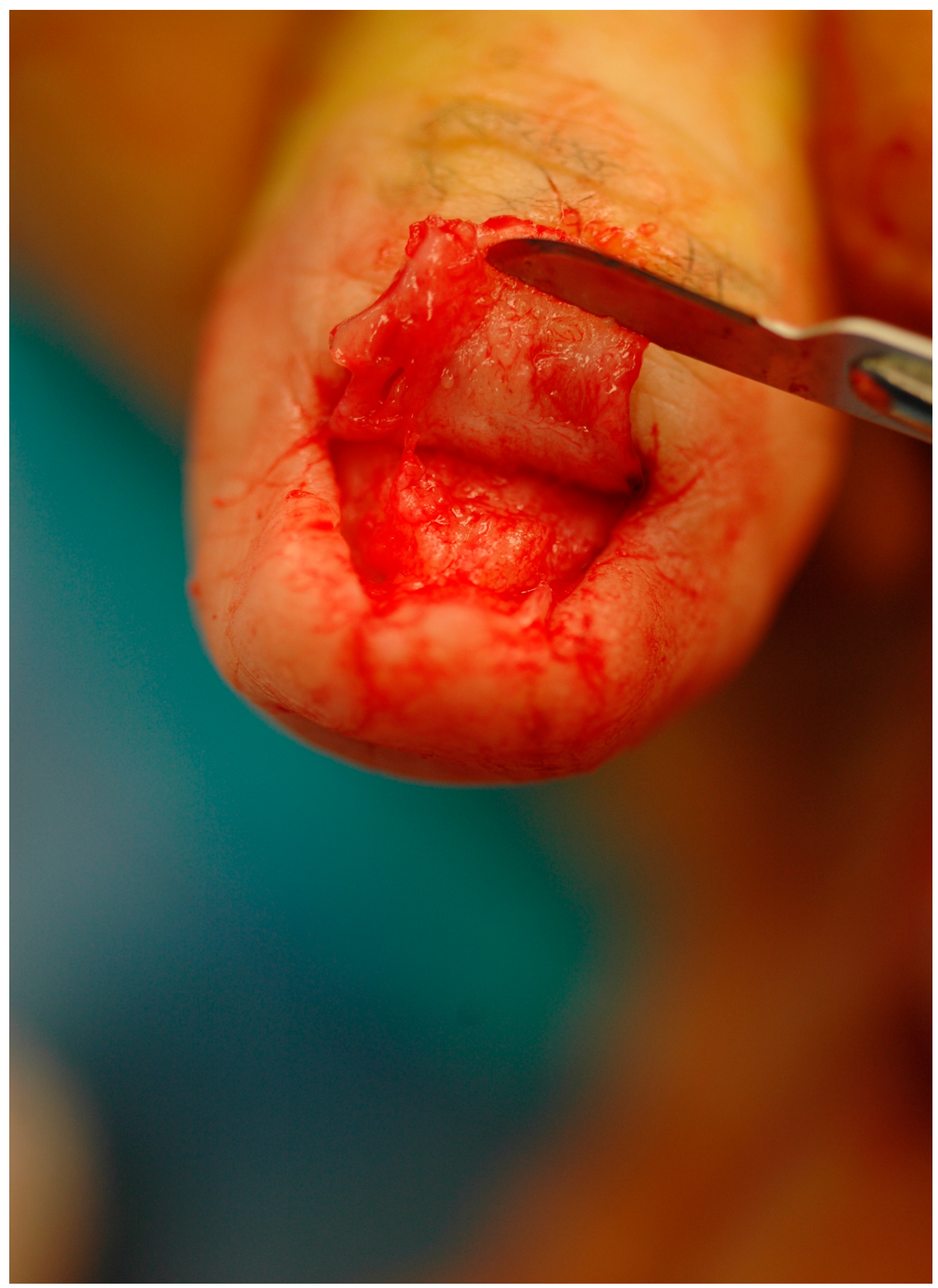

Figure 2. (Picture of nail bed elevated off distal phalanx) 


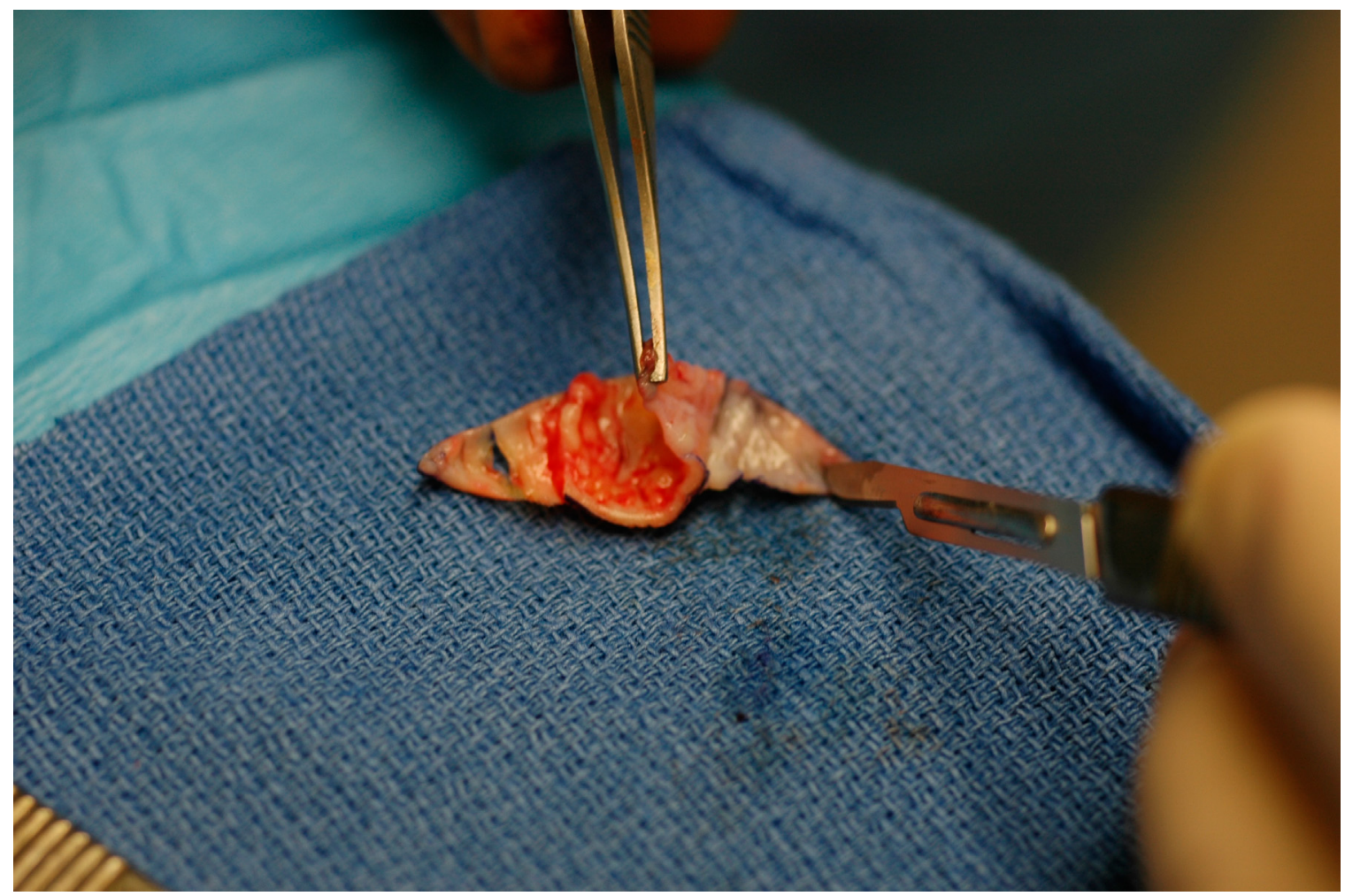

Figure 3 (Hypothenar full thickness graft being de-epithelialized)

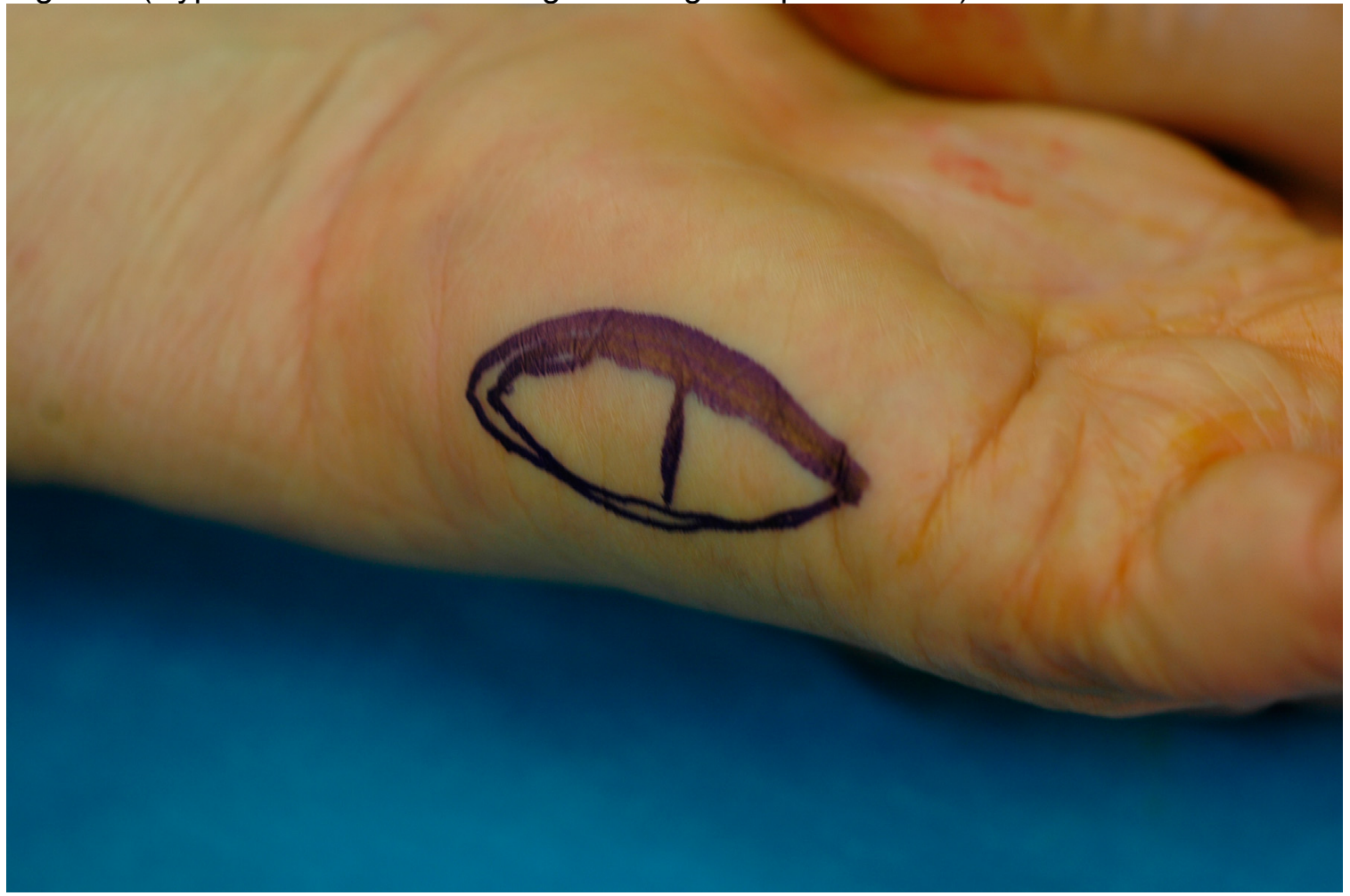

Figure 4 (Hypothenar donor site) 


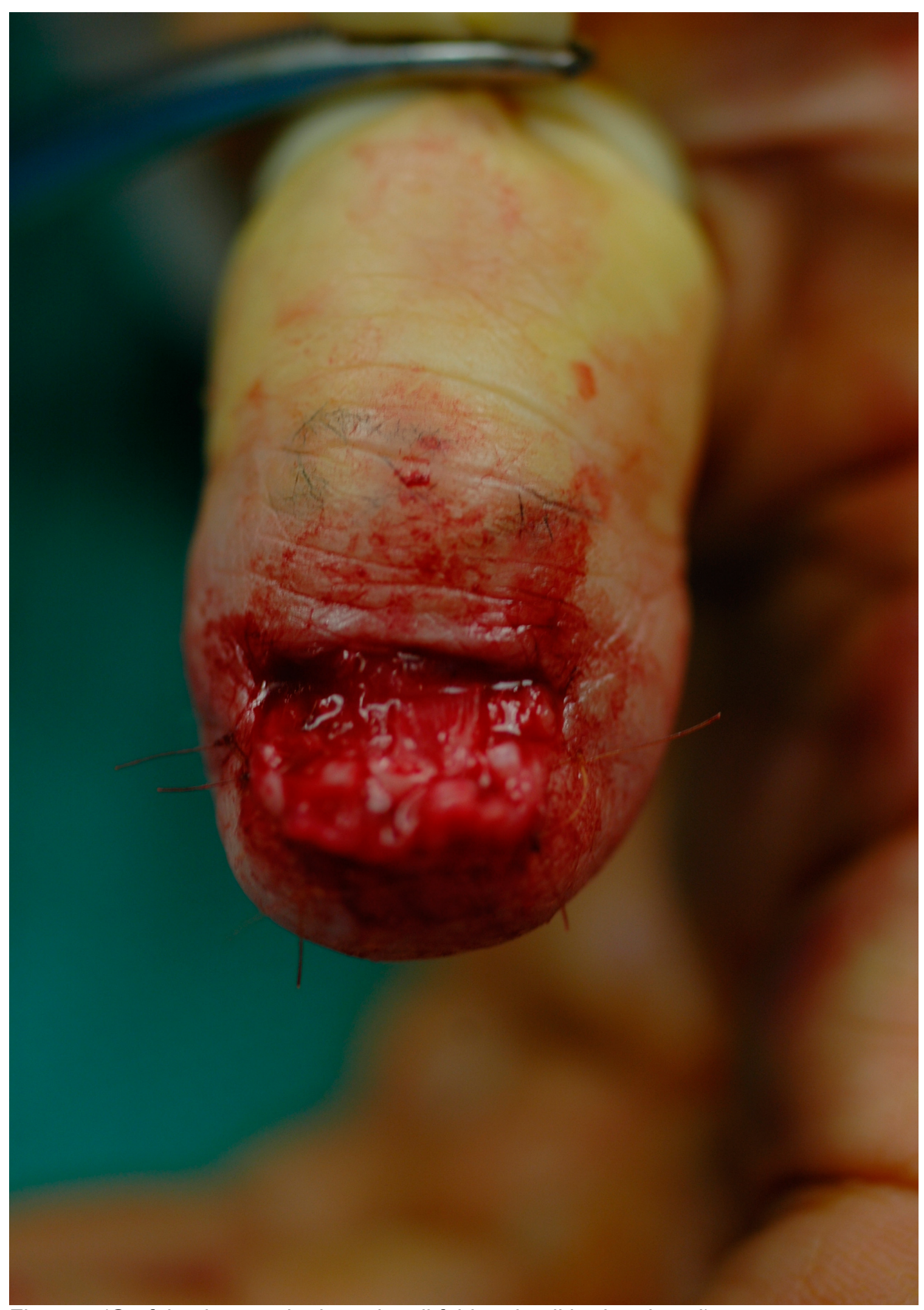

Figure 5 (Graft in place under lateral nail fold and nail bed replaced) 


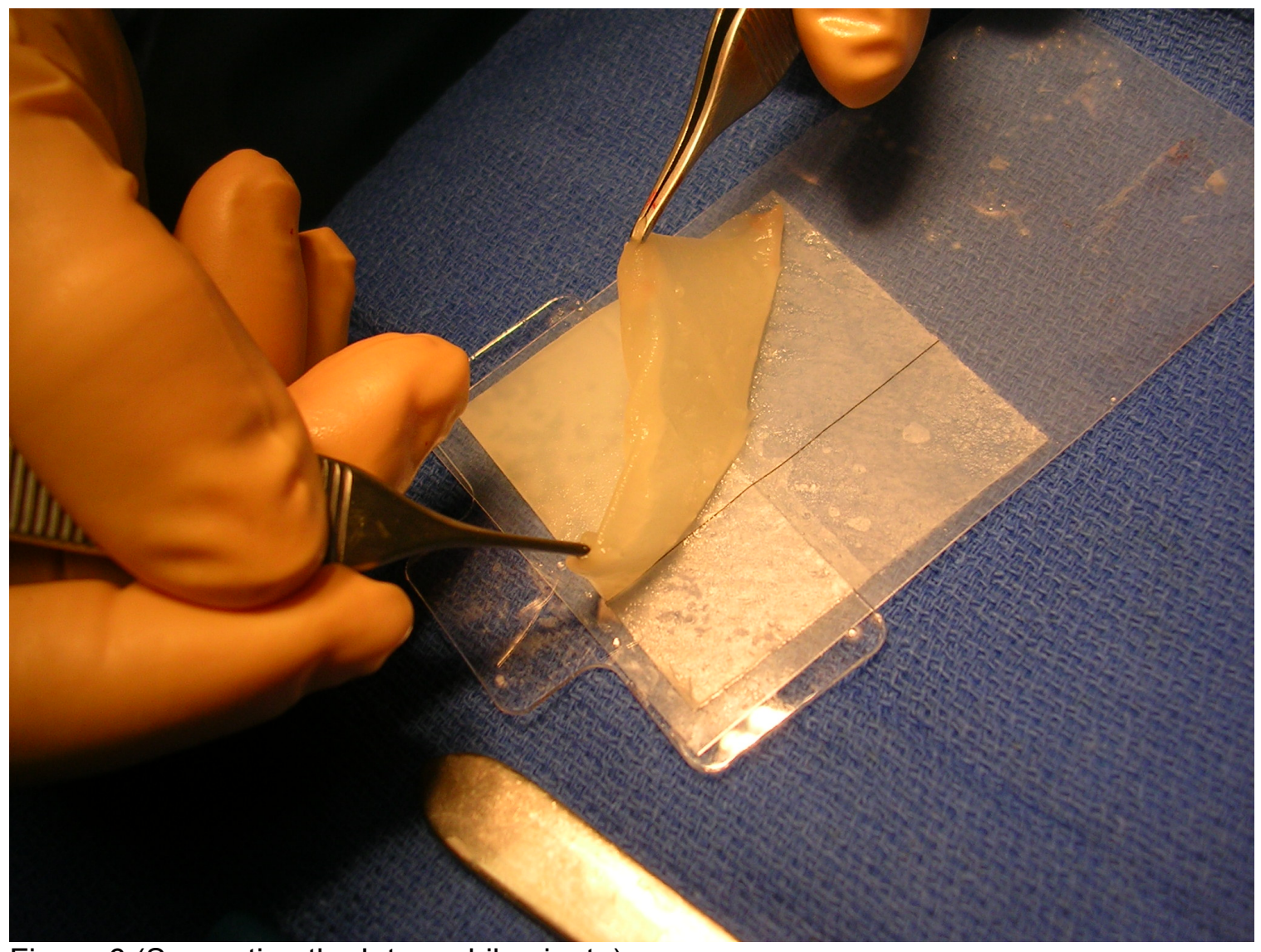

Figure 6 (Separating the Integra bilaminate)

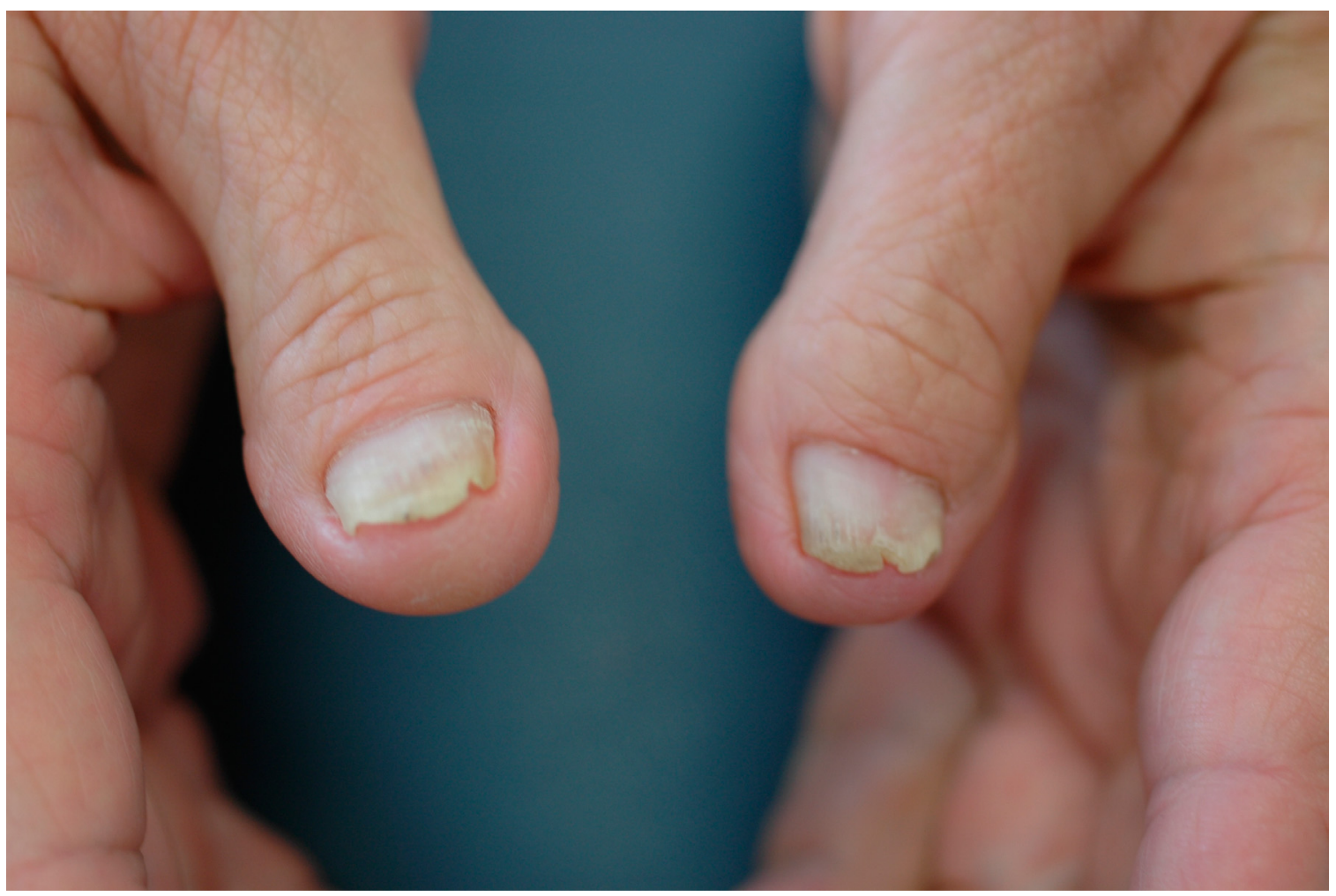


Figure 7 (Final appearance of bilateral thumb nails) \{WE NEED THIS PICTURE STILL\}

1. Brown, R.E., Zook, E.G., and Williams, J. Correction of Pincer-Nail Deformity Using Dermal Grafting. Plastic and Reconstructive Surgery. Volume 105: 1658, 2000.

2. Cornelius, C.E., III, and Shelley, W.B. Pincer nail syndrome. Archives Surgery. 96: 321, 1968.

3. Baran, R., Haneke, E., and Richert, B. Pincer Nails: Definition and Surgical Treatment. Dermatol. Surg. 27: 261, 2001.

4. Suzuki, K, Yagi, I., and Konodo, M. Surgical Treatment of pincer nail syndrome. Plast. Reconstr. Surg. 63: 570, 1979.

5. Effendy, I., Ossowski, B., and Happle, R. Pincer Nail: Conservative treatment by attachment of plastic braces. Hautarzt 44: 800, 1993.

6. Hatoko, $\mathrm{M}$ et al. Hard-Palate Mucosal Graft in the Management of Severe Pincer-Nail Deformity. Plastic and Reconstructive Surgery. Vol 112: 835, 2003. 